\title{
SISTEM NOTIFIKASI UNTUK KEAMANAN RUMAH BERBASIS SENSOR VISUAL
}

\author{
Ni Putu Diah Arista Ningsih ${ }^{1}$, Dewa Made Wiharta ${ }^{2}$, Nyoman Putra Sastra ${ }^{3}$ \\ Program Studi Teknik Elektro, Fakultas Teknik, Universitas Udayana \\ Email: putudiaharistaningsih@gmail.com ${ }^{1}$, wiharta@unud.ac.id ${ }^{2}$, putra.sastra@unud.ac.id $^{3}$
}

\begin{abstract}
ABSTRAK
Pada alat ini memanfaatkan Mikrokontroller Raspberry Pi dan Arduino Uno sebagai peralatan yang dapat memberikan tingkat keamanan yang baik untuk keamanan rumah dengan berbasis sensor visual. Alat ini menggunakan kunci elektronik dimana agar dapat melakukan pembukaan dan penguncian pintu secara elektronis berdasarkan password yang diinput menggunakan keypad. Sistem keseluruhan pada kunci elektronis sepenuhnya dikendalikan oleh Mikrokontroller Arduino Uno dan apabila password yang diinput pada keypad salah lebih dari tiga kali maka terjadi kesalahan, buzzer akan berbunyi, kamera akan mengambil gambar dan juga Mikrokontroller Raspberry Pi akan langsung mengirimkan notifikasi pada pemilik rumah melalui aplikasi Telegram. Disaat seseorang ingin berusaha masuk ke dalam rumah dengan menggunakan password yang benar atau salah kamera tetap akan secara otomatis mengambil gambar dan akan langusung mengirimkan notifikasi berupa text dan gambar pada pemilik rumah dengan melalui aplikasi Telegram. Pada kondisi jauh dari rumah sang pemilik rumah juga dapat mengetahui keadaan rumah saat ini melalui aplikasi Telegram. Pada sistem alat ini menggunakan password dimana password dapat disimpan dalam bentuk "hard code", rata-rata delay pada setiap percobaan alat ini yaitu berkisar tiga menit.
\end{abstract}

Kata kunci: Door Security, Telegram, Arduino Uno,Raspberry Pi.

\section{ABSTRACT}

In this tool utilizing the Raspberry Pi and Arduino Uno Microcontrollers as equipment that can provide a good level of security for home security with visual sensor based. This tool uses an electronic key where you can electronically open and lock the door based on the password inputted using the keypad. The whole system on the electronic key is fully controlled by the Arduino Uno Microcontroller and if the password inputted on the keypad is more than three times wrong, an buzzer will ring, the camera will take a picture and the Raspberry Pi Microcontroller will immediately send a notification to the homeowner via the Telegram application. . When someone wants to try to get into the house by using the correct or wrong password the camera will still automatically take pictures and will immediately send notifications in the form of text and images to the homeowner through the Telegram application. In conditions far from home the homeowner can also find out the current state of the house through the Telegram application. In the system this tool uses a password where passwords can be stored in the form of "hard code", the average delay in each experiment of this tool is around three minutes.

Keywords: Door Security, Telegram, Arduino Uno, Raspberry Pi.

\section{PENDAHULUAN}

Dilihat dari sudut angka kejahatan, terlihat kini angka kejahatan pencurian rumah yang sedang kosong semakin marak terjadi. Telah banyak pembuatan alat mengenai keamanan rumah yang telah diproduksi dengan keunggulan masing-masing, salah satunya dari Bagus Bayu Nur Putrawan. Dimana pada alat tersebut menggunakan keypad untuk akses keluar masuk rumah namun hanya dapat mengirimkan notifikasi berupa text melalui SMS[1]. Kini dengan melalui prototype sistem notifikasi keamanan rumah berbasis sensor visual dihrapkan dapat membuat rumah menjadi semakin aman dan dapat melindungi 
asset yang ada pada rumah yang sedang ditinggalkan oleh pemiliknya. Pemakaian password sebagai kunci elektronis dapat memberikan kemudahan dalam penggunaannya. Kunci elektronis menggunakan password ini bekerja dengan menggunakan Mikrokontroller Arduino Uno dan Mikrokontroller Raspberry Pi 3 tipe $B$, serta beberapa komponen elektronika sebagai pendukung lainnya.

Dengan menggunakan teknologi Raspberry Pi 3 tipe B yang sedang berkembang saat ini dapat dimanfaatkan untuk membuat pengamanan rumah yang lebih baik dengan teknologi berupa text, dan gambar yang akan dapat diterima oleh pemilik rumah melalui aplikasi Telegram. Maksud dari pembuatan alat ini agar dapat melakukan pembukaan dan penguncian kunci secara elektronis berdasarkan password yang diinput pada keypad sebagai syarat membuka pintu. Apabila password yang diinputkan salah lebih dari 3 kali maka sistem akan secara otomatis membunyikan alarm, kamera akan mengambil gambar dan pemilik rumah akan mendapatkan pesan berupa text dan gambar melalui aplikasi Telegram. Disaat seseorang ingin berusaha masuk ke dalam rumah dengan menginput password yang benar atau salah pada keypad maka kamera tetap akan secara otomatis mengambil gambar dan akan langusung mengirimkan notifikasi berupa text dan gambar pada pemilik rumah dengan melalui aplikasi Telegram. Penggantian password hanya dapat dilakukan pada aplikasi koding pemilik rumah. Dipilihnya aplikasi Telegram sebagai sistem pengiriman notifikasi kepada pemilik rumah, dikarenakan pada saat mengkoding hanya IP Telegram yang dapat digunakan secara aman dan mudah.

\section{KAJIAN PUSTAKA}

\subsection{Mikrokontroller Raspberry Pi 3 tipe} B

Raspberry pi yang merupakan komputer papan tunggal, memiliki ukuran sebesar kartu kredit. Menggunakan sistem operasi raspbian, dengan prosesor 700 $\mathrm{MHz}$ ARM 11. Banyak keuntungan yang didapat dari mikrokontroller raspberry $\mathrm{Pi}$, contoh saja pada alat ini raspberry pi dapat mengirimkan gambar melalui telegram bot yang dikirim pada aplikasi Telegram [1].

\subsection{Keypad}

Pada pengertiannya keypad adalah bagian penting dari suatu perangkat elektronika yang membutuhkan interaksi manusia. Keypad berfungsi sebagai interface antara perangkat (mesin) elektronik dengan manusia atau dikenal dengan istilah $\mathrm{HMI}$ (Human Machine Interface) [2].

\subsection{LCD (Liquid Crystal Display)}

Liquid Crystal Display (LCD)

merupakan sebuah alat untuk menampilkan suatu karakter yang dibangun dari dot pattern pada permukaan yang terdiri dari liquid crystalfluid diantara dua lapisan gelas (two of glasswhose inner surface). Pada saat diberi tegangan, cahaya diserap oleh crystal fluid dan kemudian membentuk dot pattern dan akan menghasilakan berupa gambar yang diinginkan [3].

\subsection{Buzzer 5V}

Buzzer adalah sebuah komponen elektronika yang berfungsi untuk mengubah getaran listrik menjadi getaran suara [4].

\subsection{Kamera jenis Logitech tipe C270}

Kamera jenis Logitech tipe C270 berfungsi untuk mengambil gambar pada sistem notifikasi keamanan rumah berbasis sensor visual. Dimana kamera ini akan mengambil gambar apabila seseorang ingin berusaha masuk kedalam rumah.

\subsection{Arduino Uno}

Arduino Uno R3 disini berperan sebagai otak dari semua alat dikarenakan semua alat kecuali kamera terhubung pada arduino Uno.

\subsection{Selenoid door lock}

Solenoid Door Lock adalah salah satu solenoid yang difungsikan khusus sebagai solenoid untuk pengunci pintu secara elektronik.

\section{$2.8 \quad$ Android}

Android merupakan sistem operasi yang memang khusus dirancang untuk smartphone dan tablet. Dimana android disini akan berfungsi sebagai penerima 
pesan dari Raspberry Pi dan Telegram Bot melalui aplikasi Telegram.

\subsection{Jaringan WIFI}

WIFI (Wirelles Fidelity) merupakan sekumpulan standar yang digunakan untuk jaringan lokal nirkabel [5].

\subsection{Telegram}

Telegram merupakan sebuah aplikasi layanan pengirim pesan instan multiplatform yang berbasis awan bersifat gratis dan nirlaba [6].

\section{METODOLOGI PENELITIAN}

Flow diagram dari sistem yang dirancang. Pada Gambar 1 dijelaskan bahwa keypad digunakan sebagai input perintah kemudian perintah tersebut proses dalam mikrokontroler Arduino Uno, selanjutnya sistem bekerja dan kamera mengambil gambar menyimpan gambar pada mikrokontroller Raspberry Pi dan hasil dari pemrosesan tersebut di keluarkan melalui aplikasi Telegram pada Handphone yang akan mengirimkan notifikasi berupa pesan dan gambar pada telepon pada pemilik rumah.

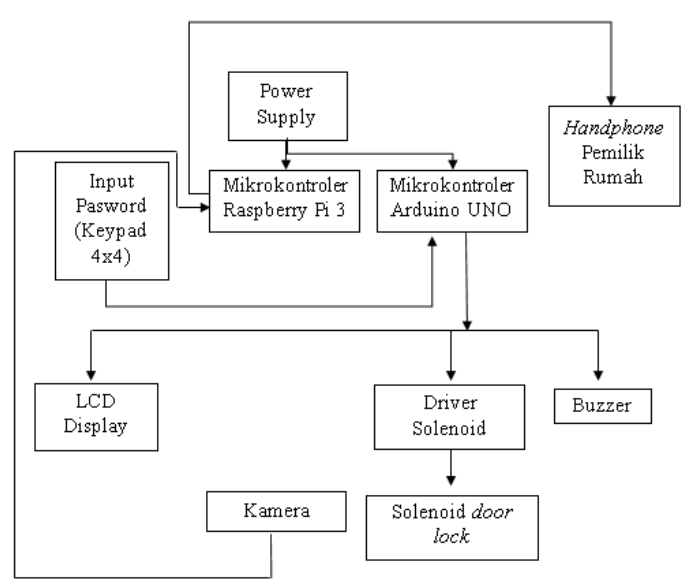

Gambar 1 Flow Diagram Sistem

Notifikasi untuk Keamanan Rumah Berbasis Sensor Visual

\subsection{Sistem Kerja Alat}

Berikut ini adalah cara kerja dari sistem notifikasi untuk keamanan rumah berbasis sensor visual yaitu:

1. Pastikan semua kabel terhubung pada aliran listrik,

2. Pastikan alat telah tersabung pada jaringan WIFI,
3. Kode password diinput pada keypad (sesuai kode password yang telah disetting sebelumnya),

4. Apabila password yang dimasukan "BENAR" maka pintu akan dapat terbuka, pada layar LCD akan bertuliskan "AKSES DITERIMA", kamera akan secara langsung mengambil gambar dan notifikasi akan dikirimkan oleh Mikrokontroller Raspberry $\mathrm{Pi} 3$ tipe B melalui aplikasi Telegram kepada pemilik rumah berupa text dan gambar,

5. Sedangkan apabila password yang dimasukan "SALAH" lebih dari 3 kali maka pintu akan tetap terkunci, pada layar LCD akan bertuliskan "AKSES DITOLAK", kamera akan secara langsung mengambil gambar dan notifikasi akan dikirimkan oleh Mikrokontroller Raspberry $\mathrm{Pi} 3$ tipe B melalui aplikasi Telegram kepada pemilik rumah berupa text dan gambar.

\subsection{Skenario Pengujian Alat}

Berikut ini adalah kegunaan dari beberapa poin rangkaian alat pada sistem notifikasi untuk keamanan rumah berbasis sensor visual:

\section{a. Keypad}

Keypad digunakan untuk input password. Caranya dengan menekan tombol pada keypad sesuai password yang telah disetting sebelumnya.

b. Liquid Cristal Display (LCD) Liquid Cristal Display (LCD) digunakan untuk mengetahui secara tertulis password benar atau salah.

c. Mikrokontroller Arduino Uno

Arduino Uno digunakan untuk memproses data, dimana Arduino Uno menjadi otak dari alat sistem notifikasi untuk keamanan rumah berbasis sensor visual.

d. Mikrokontroller Raspberry Pi 3 tipe B

Raspberry Pi 3 tibe B digunakan untuk proses mengirim data pada telegram berupa visual.

e. Buzzer

Buzzer digunakan sebagai alarm dimana agar mengetahui jika 
password yang dimasukan salah atau mengetahui jika seseorang sedang ingin berusaha masuk kedalam rumah. Buzzer ini akan aktif apabila terjadi kesalahan pada pemasukan password pada keypad.

f. Kamera

Kamera disini menggunakan kamera jenis Logitech tipe C270 dimana kamera ini berguna untuk mengambil gambar seseorang yang berusaha untuk masuk kedalam rumah. Kamera ini akan aktif apabila telah terjadi kesalahan pemasukan kode password pada keypad.

\section{HASIL DAN PEMBAHASAN}

Sistem keamanan bekerja berdasarkan password yang diinputkan oleh user ketika hendak membuka pintu. Pintu akan terbuka jika password yang diminta adalah benar. Sistem dilengkapi dengan kamera untuk menangkap gambar dan gambar tersebutakan dikirim ke perangkat mobile pemilik rumah melalui aplikasi Telegram. Selain itu, sistem juga dilengkapi dengan buzzer untuk peringatan. Pada gambar 2 terlihat gambaran visual dari alat sistem notifikasi untuk keamanan rumah berbasis sensor visual sebagai berikut ini:

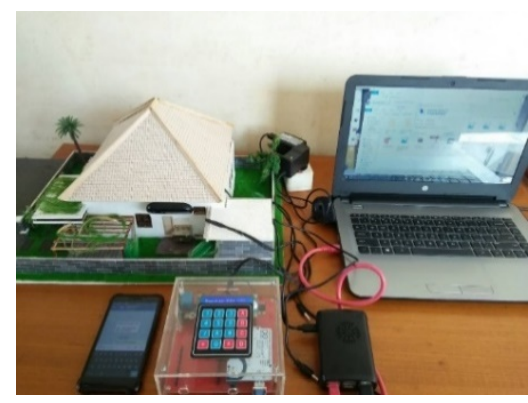

Gambar 2 Gambaran Rangkaian keseluruhan Sistem Notifikasi untuk Keamanan Rumah Berbasis Sensor Visual

\subsection{Pengujian Keypad}

Keypad berfungsi untuk mengatur tampilan pada menu LCD, mengurangi ataupun menambahkan suatu nilai. Pada

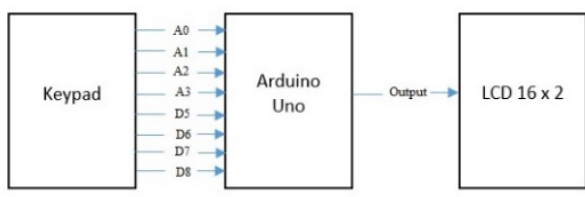

Gambar 3 adalah Blok diagram pengujian keypad sebagai berikut ini:

Gambar 3 Blok Diagram Pengujian Keypad

Sedangkan pada Gambar 4 merupakan pengujian keypad. Hasil pengujian diatas menunjukkan tomboltombol keypad dapat berfungsi dengan benar dan menampilkan sesuai yang ditekan. Berikut merupakan keterangan dan fungsi tombol keypad pada sistem notifikasi untuk keamanan rumah berbasis sensor visual.

1. Tombol angka berfungsi untuk input nilai/karakter,

2. Tombol huruf ' $A$ ' berfungsi untuk masuk ke menu yang dipilih,

3. Tombol huruf ' $B$ ' berfungsi untuk kembali ke menu sebelumnya,

4. Tombol huruf ' $C$ ' berfungsi untuk menghapus nilai/karakter.
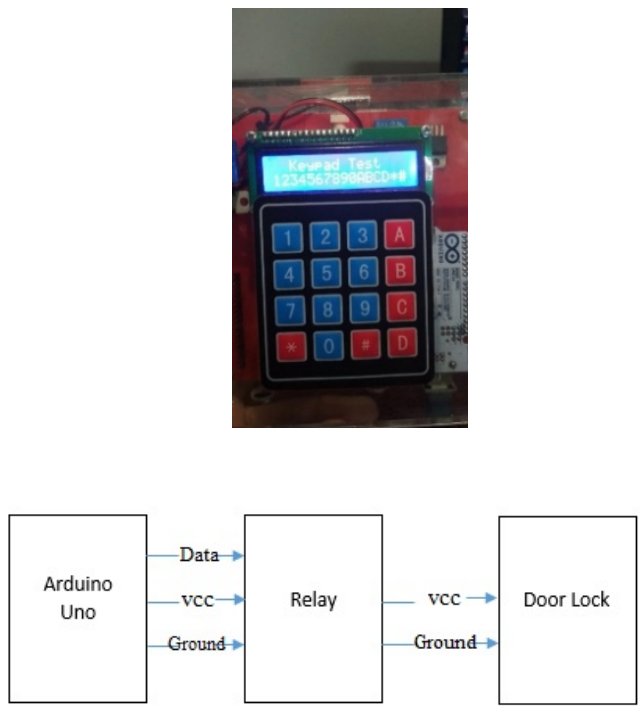

Gambar 4 Tampilan Pengujian Keypad

\subsection{Pengujian Rangkaian LCD (Liquid Crystal Display)}

Rangkaian LCD berfungsi untuk menampilkan hasil dari pengolahan data sistem mikrokontroller Raspberry $\mathrm{Pi}$. Pengujian rangkaian LCD bertujuan untuk dapat menampilkan data sesuai dengan yang direncanakan dan memudahkan dalam melakukan pengaturan sistem. Gambar blok diagram pengujian mikrokontroller Arduino Uno dengan LCD dapat dilihat pada Gambar 5 dan hasil pengujian LCD dapat dilihat pada Gambar 6. 


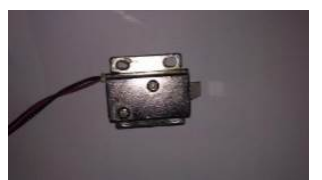

Gambar 5 Blok Diagram Pengujian LCD

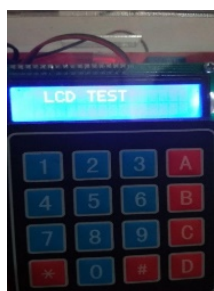

Gambar 6 Tampilan pengujian LCD

Pengujian rangkaian LCD akan dilakukan dengan memberikan data untuk ditampilkan. Data yang ditampilkan pada LCD sudah sesuai dengan yang diprogramkan, maka rangkaian dapat bekeja sesuai dengan yang dikerjakan.

\subsection{Door Lock}

Mekanisme penguncian pintu dilakukan dengan menggunakan password, dimana Door Lock akan terbuka jika password yang diinputkan benar, dan apabila password yang diinputkan salah Door Lock tidak akan dapat terbuka. Gambar blok diagram pengujian Door Lock dapat dilihat pada Gambar 7 dan hasil pengujian Door Lock dapat dilihat pada Gambar 8.

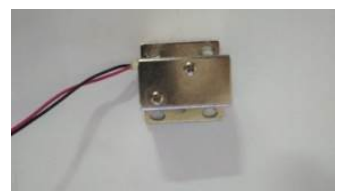

Gambar 7 Blok Diagram Pengujian Door Lock

(a)

(b)

Gambar 8 Hasil pengujian Door Lock, (a) disaat Door lock terbuka, (b) disaat door lock terkunci

\subsection{Pengujian Telegram Bot}

Dalam kaitannya Bot dengan aplikasi Telegram adalah pada saat mengirimkan sebuah gambar dalam Telegram, jika membuka peramban web dan mengetikkan kata kunci di mesin pencari kemudian mengirimkan hasilnya di Telegram, pada hal ini tinggal memanggil bot dan mengetikkan kata kunci,contoh saja: /img <gambar_yang_dicari>, maka hasilnya langsung keluar dalam aplikasi Telegram.Dengan menggunakan Telegram Bot dapat memudahkan komunikasi keseharian tanpa harus terpaku di depan komputer.

Berikut ini adalah Proses Telegram Bot pada Python terlihat pada Gambar 9 dan hasil pengujian dari Telegram Bot terlihat pada Gambar 10.

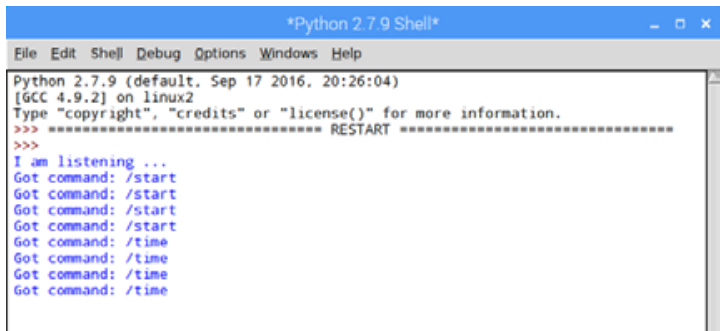

Gambar 9 Proses pengujian Telegram Bot

Gambar 10 Hasil pengujian Telegram Bot

Berikut ini adalah perintah pada program untuk pengujian Telegram Bot yaitu "import time" yang merupakan program untuk mengakses pengambilan waktu dari mikrokontroller Raspberry Pi 3

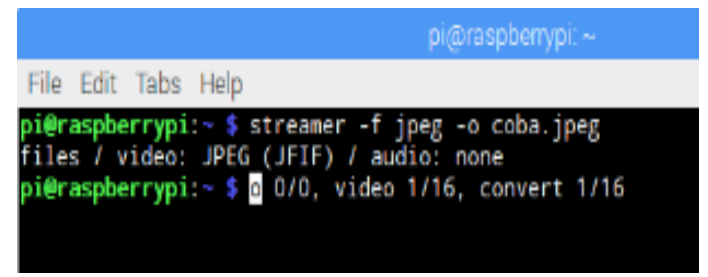

tipe B pada Telegram Bot. Dan pada Gambar 11 merupakan Hasil dari Program Telegram Bot pada aplikasi Telegram.

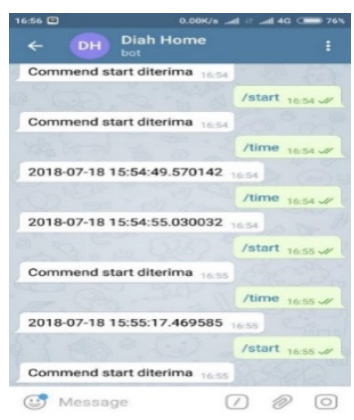


Gambar 11 Hasil dari program Telegram Bot

\subsection{Pengujian Kamera}

Pada pengujian ini kamera akan aktif apabila ada seseorang ingin mencoba untuk masuk ke dalam rumah dengan menginputkan password yang benar atau salah, dengan otomatis akan mengambil gambar. Pada kamera yang mentrigger yaitu dari program Python dimana hasil dari kamera disimpan pada directory programnya dengan nama yang sesuai dengan programnya.

Berikut pada Gambar 12 merupakan Blok Diagram dari pengujian Kamera, sedangkan pada Gambar 13 adalah hasil dari tangkapan kamera dan 14 adalah gambar yang diterima oleh pemilik rumah pada mobile phonenya yang diterima melalui aplikasi Telegram.

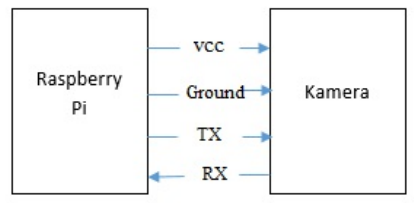

Gambar 12 Blok Diagram Pengujian Kamera

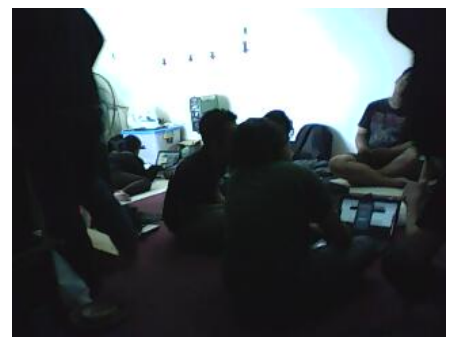

Gambar 13 Hasil Pengujian Kamera jenis Logitech tipe C270

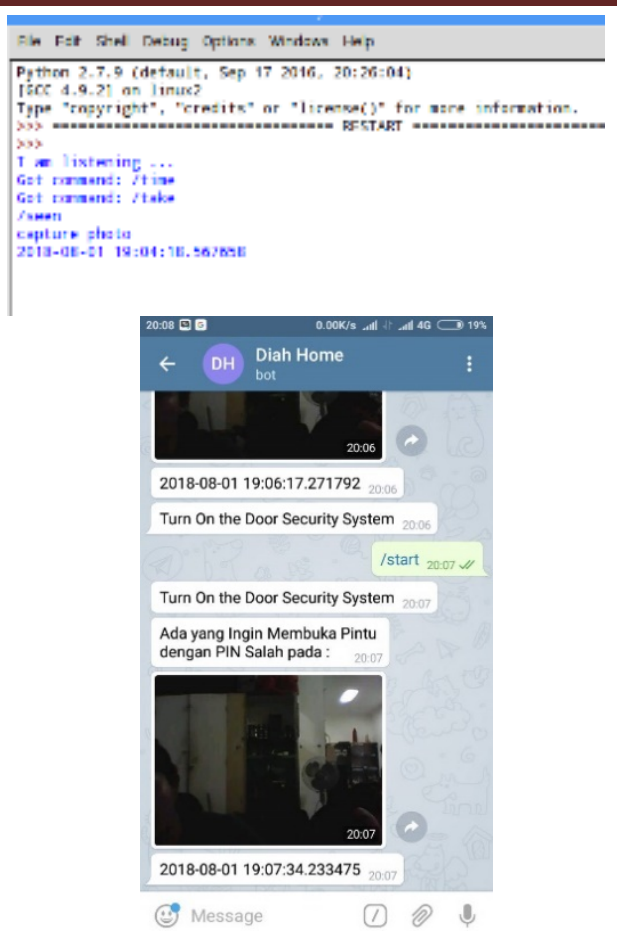

Gambar 14 Hasil Gambar yang diterima pada aplikasi Raspberry Pi 3 tipe B

\subsection{Pengujian Komunikasi}

Pada pengujian komunikasi ini adalah pengujian antara Camera menggunakan kabel untuk dapat tersambung pada Mikrokontroller Raspberry Pi 3 tipe B, dan Mikrokontroller Raspberry $\mathrm{Pi} 3$ tipe $\mathrm{B}$ menggunakan aplikasi telegram untuk dapat tersambung pada HP pemilik rumah.

Berikut pada Gambar 15 merupakan Blok Diagram dari pengujian Komunikasi, sedangkan pada Gambar 16 adalah Tampilan running dari Camera menuju Raspberry Pi dan 17 adalah Hasil Waktu pengiriman gambar dari Raspberry $\mathrm{Pi}$ menuju HP pemilik rumah melalui aplikasi Telegram Telegram.

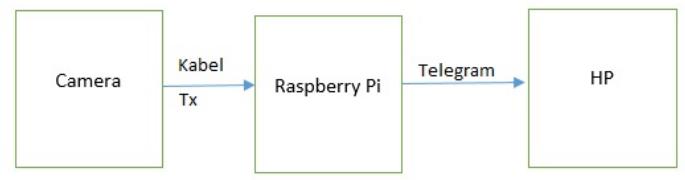

Gambar 15 Blok Diagram Pengujian Komunikasi 
Gambar 16 Tampilan running dari Camera menuju Raspberry Pi

Pada Gambar 16 menunjukan hasil waktu pengiriman gambar dari Camera menuju Raspberry $\mathrm{Pi}$ adalah pukul 19.04 WITA, pada tanggal 1 bulan agustus 2018.

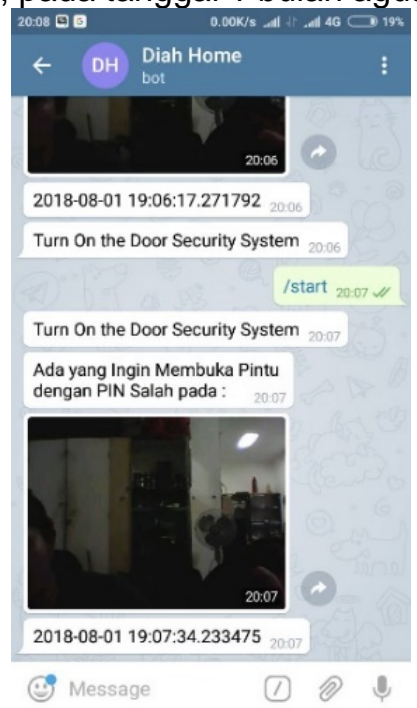

Gambar 17 Hasil Waktu pengiriman gambar dari Raspberry Pi menuju HP pemilik rumah melalui aplikasi Telegram

Pada Gambar 17 menunjukan hasil waktu yang diterima oleh HP pemilik rumah melalui aplikasi Telegram yaitu pukul 19.07 WITA, pada tanggal 1 agustus 2018. Jadi disini terdapat selisih waktu antara camera mengambil gambar dengan HP pemilik rumah yang menerima gambar, selisih itu berkisar 3 menit.

Berikut adalah gambar pengujian komunikasi pada pemilik rumah apabila pemilik rumah berkeinginan untuk mengetahui kondisi rumahnya dalam kondisi jarak jauh.

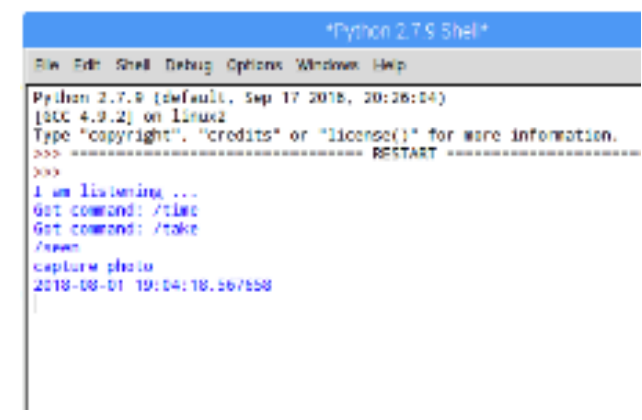

Gambar 18 Tampilan running yang terdapat pada pemrograman pengecekan waktu dan pengecekan kondisi rumah

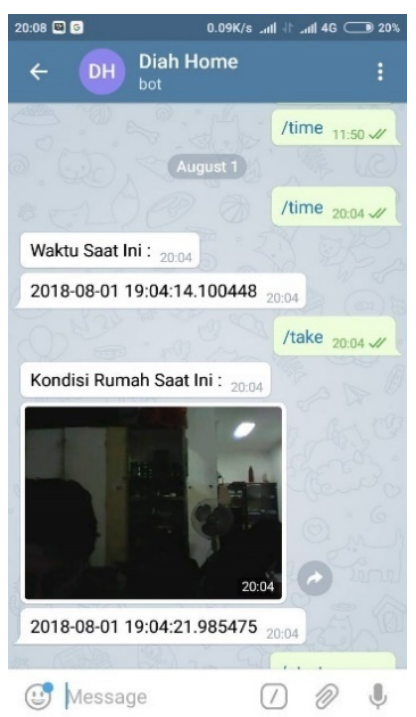

Gambar 19 Hasil pengiriman gambar dari Raspberry Pi menuju HP pemilik rumah dalam pengecekan kondisi rumah jarak jauh melalui aplikasi Telegram

Pada Gambar 19 merupakan hasil pengiriman gambar dari Raspberry $\mathrm{Pi}$ menuju HP pemilik rumah. Dimana cara untuk mengetahui kondisi rumah saat ini yaitu dengan cara mengetik /time pada aplikasi Telegram untuk mengetahui waktu pengambilan gambar dan mengetik /take pada aplikasi Telegram untuk memerintah kamera mengambil gambar saat ini.

\subsection{Pengujian Keamanan Pintu}

Sistem yang dibangun dilengkapi dengan data-data pemilik rumah yang masing- masing memiliki password yang berbeda. Password ini di rancang untuk penghuni rumah. Tabel 1 menunjukkan password untuk tiap user yang tersimpan dalam sistem.

Tabel 1 Pengujian Kode Password pada Keypad 
Selain kode yang telah disetting seperti tabel diatas maka kunci pintu tidak akan dapat terbuka atau akses ditolak.

Pada Gambar 20 merupakan tampilan pada saat password diinputkan pada keypad dan terlihat pada layar LCD.

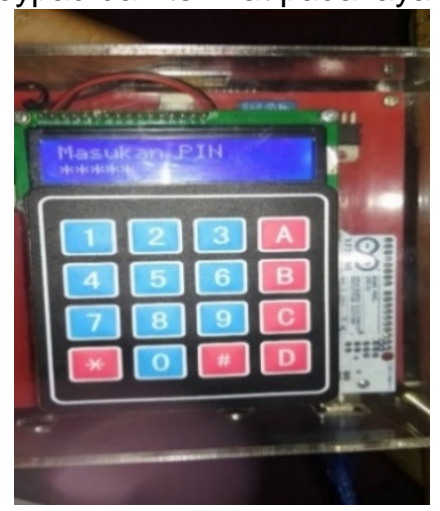

Gambar 20 Tampilan Pengujian kode Password saat memasukan kode pin pada keypad terlihat pada layar LCD

\section{SIMPULAN}

Dari hasil prototype alat sistem notifikasi untuk keamanan rumah berbasis sensor visual ini mendapatkan kesimpulan dimana rancangan sistem pengaman rumah ini menggunakan password, dimana kode password dapat disimpan dalam bentuk "hard code". Sistem pengaman rumah ini dilengkapi dengan notifikasi dan buzzer. Apabila terjadi kesalahan lebih dari tiga kali maka akses akan ditolak.Suatu notifikasi berupa text dan gambar akan diterima oleh pemilik rumah melalui aplikasi telegram. Pada saat pengujian alat rata-rata waktu delay pada setiap percobaan alat ini yaitu berkisar 3 menit.

Alat ini akan lebih baik lagi apabila yang pertama pada input password dapat dilakukan menggunakan koneksi wireless seperti WIFI atau SMS ( Short Message Service), tanpa harus menekan tombol keypad secara langsung. Menambahkan fitur tersebut agar dapat melakukan pembukaan pintu secara jarak jauh. Kedua yaitu sistem keamanan pada keypad agar mampu mengisi ulang (charge) baterai untuk keypad apabila listrik sedang mati. Ketiga yaitu menambahkan fitur aplikasi pada smartphone untuk dapat mengubah kata sandi langsung pada mobile phone pemilik rumah. Dan yang terakhir yaitu dalam pengembangan untuk membuka dan mengunci pintu secara otomatis alangkah baiknya tidak terfokus pada satu pintu dapat juga dilakukan pada beberapa pintu masuk atau jendela lainnya yang terdapat pada rumah.

\begin{tabular}{|l|l|l|l|}
\hline Password & Akses & Aksi & User \\
\hline 666666 & $\begin{array}{l}\text { Akses } \\
\text { diterima }\end{array}$ & $\begin{array}{l}\text { Kunci } \\
\text { Pintu } \\
\text { Terbuka }\end{array}$ & $\begin{array}{l}\text { Login } \\
\text { Bapak }\end{array}$ \\
\hline 777777 & $\begin{array}{l}\text { Akses } \\
\text { diterima }\end{array}$ & $\begin{array}{l}\text { Kunci } \\
\text { Pintu } \\
\text { Terbuka }\end{array}$ & $\begin{array}{l}\text { Login } \\
\text { lbu }\end{array}$ \\
\hline 888888 & $\begin{array}{l}\text { Akses } \\
\text { diterima }\end{array}$ & $\begin{array}{l}\text { Kunci } \\
\text { Pintu } \\
\text { Terbuka }\end{array}$ & $\begin{array}{l}\text { Login } \\
\text { Anak }\end{array}$ \\
\hline
\end{tabular}

\section{DAFTAR PUSTAKA}

[1] Nur Putrawan, Bagus Bayu, (2006) "Perancangan Sistem Pengamanan Rumah Menggunakan Keypad dan Teknologi SMS berbasis Mikrokontroller".

[2] Anonim, " pengertian keypad", http://elektronikadasar.web.id/artikelelektronika/keyp ad, diakses pada 25 November 2017

[3] Anonim," Pengertian LCD 16x2, https://teknikelektronika.com/pengert ian-Icd-liquid-crystal-display-prinsipkerja-Icd/ diakses pada tanggal 21 November 2017

[4] Indraharja, (2012), "pengertian buzzer", https://indraharja.wordpress .com/2012/01/07/pengertianbuzzer/, diakses pada tanggal 21 November 2017

[5] Anonim,"Pengertian jaringan WIFI",http://www.academia.edu/158 50534/Wifi_adalah_singkatan_dari_ Wireless_Fidelity, diakses pada tanggal 21 November 2017

[6] Anonim,"Pengertian Telegram"https://id.wikipedia.org/wiki/ Telegram_(aplikasi) diakses pada tanggal $21 \quad$ November 2017 